\title{
Noninvasive Imaging Tools in the Diagnosis and Treatment of Skin Cancers
}

\author{
Renato Marchiori Bakos ${ }^{1} \cdot$ Tatiana Pinto Blumetti $^{2} \cdot$ Rodrigo Roldán-Marín $^{3} \cdot$ Gabriel Salerni $^{4}$
}

Published online: 30 October 2018

(c) The Author(s) 2018

\begin{abstract}
In the 1980s, the increasing incidence of skin cancers prompted the development of noninvasive medical devices to improve skin cancer diagnosis in daily dermatology practice. As a result of the development of these noninvasive techniques, diagnosis is now established earlier and with better accuracy. These advances are of great benefit to high-risk patients, who previously would have had to undergo several excisions. In this review, we focus on the classic technique of dermoscopy and the more recent digital version, as well as on advanced noninvasive imaging techniques, such as reflectance confocal microscopy and optical coherence tomography. On the basis of their specific features, these noninvasive medical devices can be used not only to diagnose and monitor melanoma and nonmelanoma skin cancers but also to choose the best therapy and follow the patient's response to treatment in vivo.
\end{abstract}

\section{Key Points}

Dermoscopy, as digital dermoscopy, is a powerful in vivo noninvasive technique for early detection of both nonpigmented and pigmented lesions. Once fully trained, physicians may benefit from recognizing tumor patterns and, consequently, in management decisions.

Reflectance confocal microscopy and optical coherence tomography are novel techniques in the evaluation of skin tumors. They may also improve accuracy in detecting cutaneous neoplasms in different scenarios.

Renato Marchiori Bakos

rbakos@hcpa.edu.br

Tatiana Pinto Blumetti

tatianadermato@gmail.com

Rodrigo Roldán-Marín

roroderm@yahoo.com

Gabriel Salerni

gabriel.salerni@e-derma.com.ar

1 Hospital de Clínicas de Porto Alegre, Universidade Federal do Rio Grande do Sul, Rua Ramiro BArcellos 2350,

Porto Alegre, RS 90035-007, Brazil

\section{Introduction}

Specific features of skin lesions have been uncovered by the dermatoscope and organized into 'dermoscopic patterns' [1] to allow benign and malignant lesions to be distinguished with more than $90 \%$ accuracy, depending on the lesion type and the experience of the dermatologist [2-6]. Nevertheless, missing or ambiguous dermoscopic patterns may lead to false or misdiagnosis in some cases, such as in patients with featureless melanomas. Although the guidelines still recommend histopathologic analysis, suspicious lesions may now be examined further using an advanced noninvasive technique, such as reflectance confocal microscopy (RCM)

2 Skin Cancer Department, AC Camargo Cancer Center, Rua Prof. Antônio Prudente, 211-Liberdade, São Paulo, SP 01509-010, Brazil

3 Dermato-Oncology Clinic, Faculty of Medicine, Universidad Nacional Autónoma de México, Circuito Escolar s/n (Edificio Consejo Técnico Facultad de Medicina), Avenida Universidad 3000, Coyoacan, 04510 Mexico City, Mexico

4 Hospital Provincial del Centenario de Rosario, Argentina, Diagnóstico Médico Oroño, Bv. Oroño 1515, 2000 Rosario, Argentina 
or optical coherence tomography (OCT). Examination with these techniques increases the accuracy of diagnosis and allows unnecessary biopsies to be avoided. These techniques rely on medical devices that offer different levels of analysis in vivo- the deeper the observation, the lower the resolution (Table 1). The parameters of each medical device will thus determine the most suitable technique to assess the equivocal lesion. In this review, we describe the parameters and applications of each technique, according to their role in skin cancer diagnosis, patient monitoring, treatment choice. and patient response to treatment.

\section{Skin Cancer Diagnosis and Monitoring}

\subsection{Dermoscopy and Digital Dermoscopy: Description}

Dermoscopy (also called dermatoscopy, epiluminescence microscopy, or incident light microscopy) is a noninvasive microscopic technique based on the use of incident light and the reduction of specular reflectance, either with an interface fluid (nonpolarized dermoscopy) or a polarized light filter (polarized dermoscopy). Using a dermatoscope, the pigmented structures of the epidermis, the epidermal-dermal junction, and the superficial dermis can be visualized in vivo (Table 1). Dermoscopy, which is now a standard of evaluation, has greatly improved the diagnostic accuracy of both nonpigmented and pigmented lesions. Meta-analyses performed in experimental [3] and clinical settings [4] have demonstrated that dermoscopy increases the sensitivity and specificity of the diagnosis, favors the recognition of benign from malignant lesions, and consequently decreases the rate of benign lesion biopsy [6, 7]. Furthermore, the dermatoscope is easy to manipulate and does not prolong observation times. Performing a whole-body dermoscopic evaluation was shown to be more accurate than doing a first naked-eye screen of the lesions that need to be examined further with the dermatoscope [8]. The combination of total body photography and digital dermoscopy, called the "twostep follow-up method', enables mapping of all lesions and their evolution over time to be followed. This is particularly important because nevi, including atypical (dysplastic) nevi, tend to be stable, whereas malignant melanomas show changes in size, color, and/or dermoscopic structures over time. In addition, de novo lesions can be identified and monitored. Therefore, the 'two-step follow-up method' is most useful in patients with multiple nevi, those with a personal and/or family history of melanoma, or in those with a strong genetic susceptibility for developing melanoma.

\subsubsection{Diagnosis and Monitoring of Melanocytic Lesions with Dermoscopy}

Although the diagnosis of a late-stage melanoma is straightforward, the prompt identification of early-stage melanoma is crucial to avoid deep dermis invasion and metastatic spread, thus reducing the cost of therapy [9] and improving survival rates [10]. For melanoma recognition, dermoscopy proved to be a powerful technique as its accuracy is

Table 1 Noninvasive techniques for diagnosing and monitoring skin cancers

\begin{tabular}{|c|c|c|c|c|c|}
\hline \multirow[t]{2}{*}{ Technique (date) } & \multirow{2}{*}{$\begin{array}{l}\text { Cost (most likely } \\
\text { users) }^{\mathrm{a}}\end{array}$} & \multicolumn{2}{|l|}{ Parameters } & \multirow{2}{*}{$\begin{array}{l}\text { Advantages/limita- } \\
\text { tions }\end{array}$} & \multirow{2}{*}{$\begin{array}{l}\text { Appropriate to } \\
\text { diagnose }\end{array}$} \\
\hline & & Resolution & Depth & & \\
\hline Dermoscopy (1987) & $\begin{array}{l}\$ 0.1-\$ 2 \mathrm{~K} \text { (all derma- } \\
\text { tologists) }\end{array}$ & $\begin{array}{l}\text { Low pigmented } \\
\text { structures }\end{array}$ & $\begin{array}{l}\text { Low epidermal-der- } \\
\text { mal junction and } \\
\text { superficial dermis }\end{array}$ & $\begin{array}{l}\text { Rapid/no transversal } \\
\text { images at depth }\end{array}$ & $\begin{array}{l}\text { Melanoma } \\
\text { Basal cell carcinoma } \\
\text { Actinic keratosis }\end{array}$ \\
\hline $\begin{array}{l}\text { Digital dermoscopy } \\
\text { (1991) }\end{array}$ & $\begin{array}{l}\$ 10-\$ 250 \mathrm{~K} \text { (pig- } \\
\text { mented lesion } \\
\text { experts) }\end{array}$ & & & $\begin{array}{l}\text { Rapid screening of the } \\
\text { whole body/large } \\
\text { dataset to interpret }\end{array}$ & $\begin{array}{l}\text { Melanoma } \\
\text { Monitoring of former } \\
\text { lesions + identifica- } \\
\text { tion of new lesions }\end{array}$ \\
\hline $\begin{array}{l}\text { Confocal microscopy } \\
\text { (2001) }\end{array}$ & $\begin{array}{l}\$ 100 \mathrm{~K} \text { (all derma- } \\
\text { tologists willing to } \\
\text { invest in the neces- } \\
\text { sary training) }\end{array}$ & $0.5-1 \mu \mathrm{m}$ cells & $\begin{array}{l}200-300 \mu \mathrm{m} \text { papillary } \\
\text { dermis }\end{array}$ & $\begin{array}{l}\text { Good correlation of } \\
\text { transversal sections } \\
\text { with histology/depth } \\
\text { limited }\end{array}$ & $\begin{array}{l}\text { Melanoma } \\
\text { Basal cell carcinoma } \\
\text { Actinic keratosis } \\
\text { Squamous cell carci- } \\
\text { noma }\end{array}$ \\
\hline 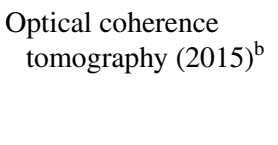 & $\begin{array}{l}\text { \$130-\$180 K (a } \\
\text { few academic } \\
\text { dermatologists })^{b}\end{array}$ & $10 \mu \mathrm{m}$ structures & $2 \mathrm{~mm}$ reticular dermis & $\begin{array}{l}\text { Good correlation of } \\
\text { axial sections with } \\
\text { histology/resolution } \\
\text { limited }\end{array}$ & $\begin{array}{l}\text { Basal cell carcinoma } \\
\text { Squamous cell carci- } \\
\text { noma }\end{array}$ \\
\hline
\end{tabular}

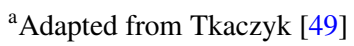

${ }^{\mathrm{b}}$ This device may be used to diagnose/evaluate skin tumors in clinical practice but is still under evaluation 
approximately $50 \%$ higher than that of the naked-eye \{mean log odds ratio 4.0 [95\% confidence interval (CI) 3.0-5.1] versus 2.7 [95\% CI 1.9-3.4], $p=0.001\}$ [3].

In accordance with the meta-analysis of Gandini et al. [11], high-risk melanoma patients can first be distinguished by counting the number of nevi on the arm and identifying their subtype (e.g. atypical nevus). A patient with 11-15 common nevi on the arm is likely to have a body total of more than 50 nevi and a fivefold higher risk of developing melanoma than a person without any nevi on the arm [pooled relative risk (RR) $4.82,95 \%$ CI 3.05-7.62], whereas a patient with any atypical nevi has a tenfold higher risk of developing melanoma than a patient with no atypical nevi (RR 10.12, 95\% CI 5.04-20.32) [11]. Furthermore, the number of atypical nevi greatly increases the risk of melanoma from 1.60 (95\% CI 1.38-1.85) for one atypical nevus to 10.49 (95\% CI 5.05-21.76) for five atypical nevi [11]. Nevi number varies according to the patient phototype, their genetic background, and their level of ultraviolet exposure [12].

The first dermoscopic evaluation method was introduced by Pehamberger et al. [1], who established the localized and global patterns associated with melanomas. The multicomponent pattern, combining three or more different features, used to be the most recognized; however, dermoscopic pattern recognition requires training, and diagnostic algorithms may be helpful for new users. The algorithm of Stoltz et al. [13], also known as the ABCD (asymmetry, borders, color, dermoscopic structures) rule for dermoscopy, defines benign, suspicious, and malignant lesions according to a quantitative score, whereas the method of Menzies et al. [14] relies on the absence of two negative criteria and the presence of at least one positive criterion to distinguish malignant melanoma. In addition, the seven-point checklist of Argenziano et al. [15], consisting of three major and four minor criteria to identify benign from malignant lesions on the basis of a score, was the first to incorporate the vascular pattern into a score. A virtual Consensus Net Meeting on Dermoscopy, involving 40 experienced professionals and the diagnosis of 108 lesions, concluded that in comparison with algorithms, pattern analysis was the most sensitive and specific diagnostic method for distinguishing benign lesions from malignant melanocytic lesions [16].

In contrast with the stability of common nevi, malignant melanomas will evolve over time (Fig. 1), which reinforces the need for regular dermoscopic surveillance of high-risk patients. This specific feature of malignancy was tested with the 'two-step method of digital follow-up', which combines total body photography and digital dermoscopy. The importance of detecting new lesions was highlighted by the prospective surveillance study conducted by Salerni et al. [17] in 618 high-risk melanoma patients (11,396 lesions) from 1999 to 2008; among the 1152 excised lesions that were analyzed, $32.4 \%$ (373/1152) corresponded to de novo lesions. Overall, most lesions $(63.2 \% ; 728 / 1152)$ were excised because of changes in dermoscopic patterns, with asymmetric enlargement being the most frequent change $(57.4 \%$; 418/728). It is noteworthy that malignant melanomas were found to occur at any time over the 10-year surveillance period, thus supporting the need for long-term monitoring of high-risk patients [18]. These data were confirmed in a meta-analysis of two short-term and 12 longterm studies using sequential digital dermoscopy to follow up 52,739 melanocytic skin lesions [19]. In this analysis, the mean biopsy rate was lower in medium/long-term follow-up studies (3-96 months) than in short-term follow-up studies (2-4.5 months) [5.2 vs. $17.6 \%$ ], with an overall mean of below one biopsy per patient. Digital follow up was therefore found to be efficacious in early-stage melanoma detection and efficient for obtaining a low rate of excision.

Dermoscopy, as digital dermoscopy, therefore appears to be a powerful technique for detecting melanomas early and quickly, and the recent dermatology guidelines attributed a high level of evidence to its general use [20]. Dermoscopy beginners may first refer to diagnosis algorithms, and, once fully trained, switch to pattern recognition. For the monitoring of high-risk patients, the 'two-step method of digital follow-up' is recommended.

\subsubsection{Diagnosis of Nonmelanocytic Skin Cancer with Dermoscopy}

2.1.2.1 Basal Cell Carcinomas Basal cell carcinoma (BCC) is the most common nonmelanocytic skin cancer (NMSC) worldwide [21]. The management of BCC relies on several factors: tumor size and site, definition of the margins, histologic subtype and features of aggression, failure of a previous treatment, and immunosuppression status [22]. Dermoscopy might be helpful in this scenario for distinguishing between the nodular, infiltrative, or superficial BCC lesion subtypes [23]. Nonpigmented nodular lesions are the most common subtype and are most frequently located on the head and neck. Clinically, these lesions present as pearly, shiny papules or nodules with telangiectasias (Fig. 2a). By dermoscopy, several thick arborizing telangiectasias branching over the lesion are observed (Fig. 2e, f). In addition, friability may generate ulceration of the lesion. Both clinical and dermoscopic aspects together are highly indicative of nodular BCC (Fig. 2b, g). Superficial nonpigmented BCC lesions are clinically defined by friable, scaly, and flat erythematous plaques (Fig. 2c). Further dermoscopic examination usually shows short and superfine telangiectasias or linear vessels over a reddish background with multiple microerosions that also occur due to friability (Fig. 2h). Finally, infiltrative BCC lesions present as indurated plaques or depressions with illdefined borders and atrophy (Fig. 2d). By dermoscopy, fine and scattered telangiectasias branching over the lesion are observed over a white fibrosis-induced background (Fig. 2i). 

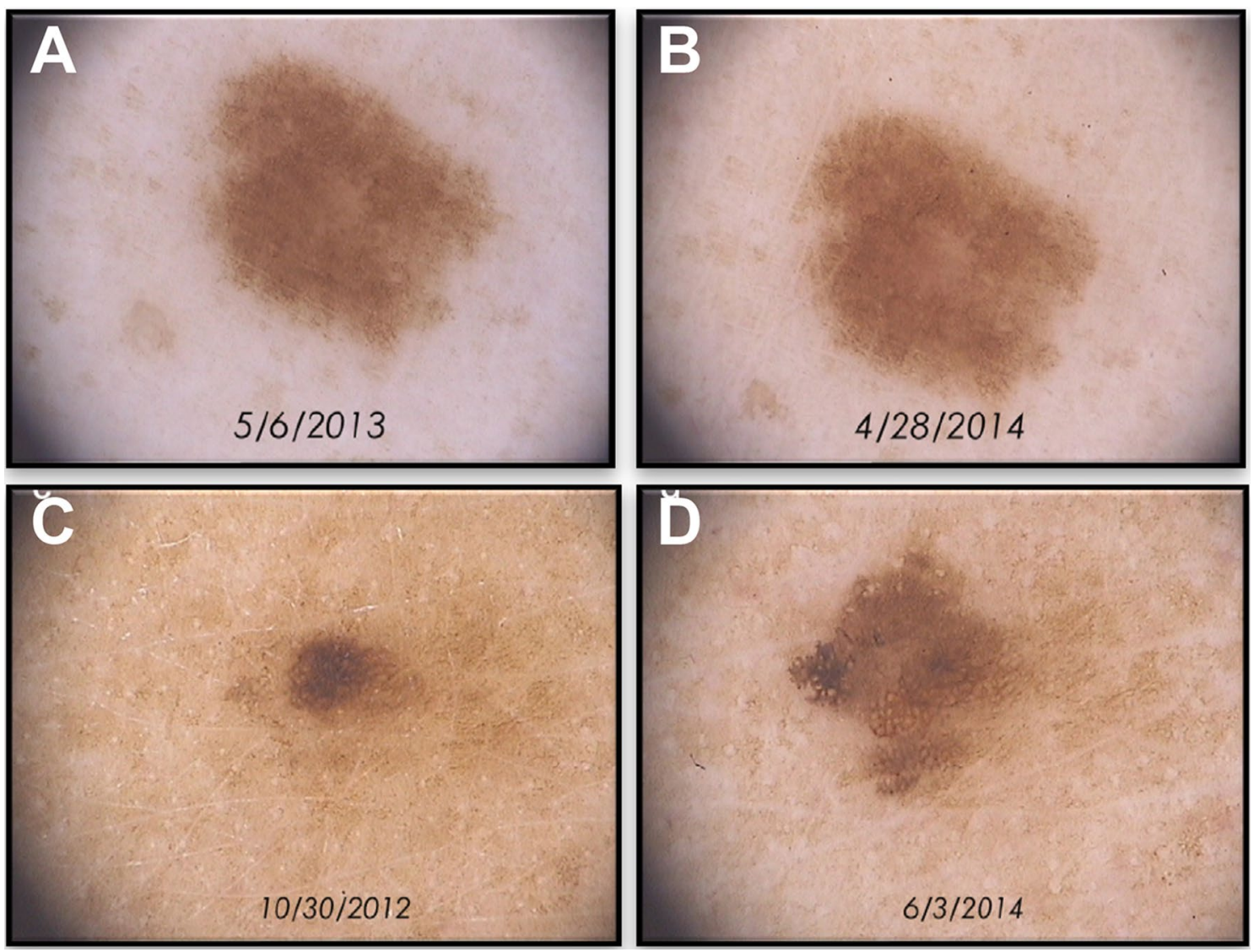

Fig. 1 Follow-up of benign and malignant pigmented lesions by dermoscopy. Stability of a benign lesion over time (a, b). Change of a pigmented lesion over time suggesting malignancy $(\mathbf{c}, \mathbf{d})$. Dermoscopy original magnification $\times 20$

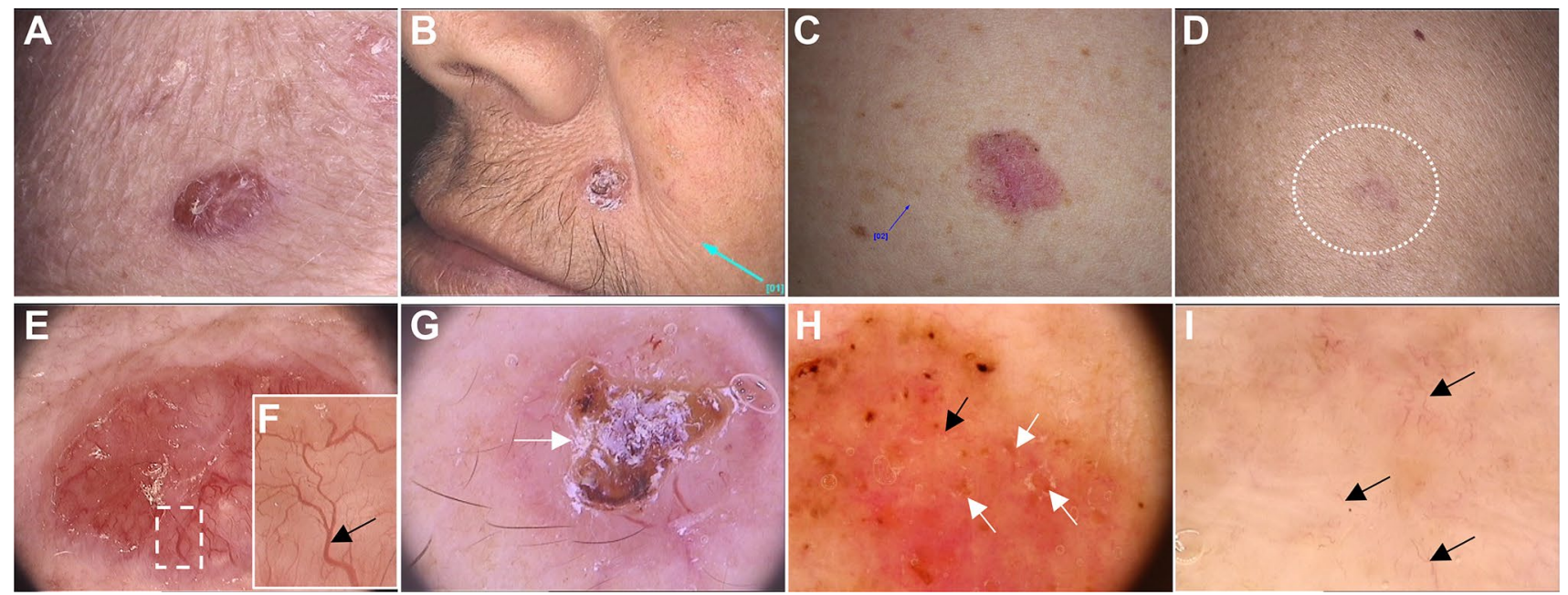

Fig. 2 Facial nonpigmented basal cell carcinoma lesions. Photographs of nodular $(\mathbf{a}, \mathbf{b})$, superficial $(\mathbf{c})$, and infiltrative $(\mathbf{d})$ basal cell carcinoma lesions and the corresponding dermoscopic images (original magnification $\times 20$, Fotofinder systems): thick arborizing telangi- ectasias branching over the lesion (e) and at high magnification (black arrow) (f), and ulceration (white arrow) (g). Microerosions (white arrows) and super fine, short telangiectasias (black arrow) (h). Fine and scattered telangiectasias (black arrows) (i) 
Pigmented BCC lesions may also be distinguished from other pigmented skin lesions by dermoscopy. On the basis of the classic algorithm of Menzies et al. [24], pigmented BCC lesions should not have a pigmented network, but should have at least one of the following six positive criteria (Fig. 3a-f): ulceration, large blue-gray ovoid nests, multiple blue-gray globules, maple leaf-like areas, spoke-wheel areas, and arborizing telangiectasias. The differential diagnosis can be illustrated by the pigmented lesion surrounded by angiomas shown in Fig. 3g. This lesion may be clinically misclassified as a thrombosed angioma, whereas the dermoscopic examination clearly reveals the maple leaf-like pattern found in pigmented $\mathrm{BCC}$ and the absence of angioma dermoscopic structures such as the lacunae (Fig. 3h, i).

2.1.2.2 Keratinocytic Tumors Keratinocytic tumors are a group of lesions encompassing actinic keratosis (AK), intraepidermal carcinoma (IEC; also called Bowen's disease or in situ squamous cell carcinoma [SCC]), invasive SCC, and keratoacanthoma (Table 2). AK lesions are dysplastic proliferations of keratinocytes that may potentially progress to SCC [25]. AK lesions are frequently treated with topical agents, while invasive SCCs primarily require surgical therapy. It is therefore critical to make an early diagnosis of AK, which has been greatly improved by dermoscopy [26]. Zalaudek et al. [27] identified a specific dermoscopic pattern associated with facial AK, namely the 'strawberry pattern', combining four criteria: a red pseudonetwork, white scales, fine linear-wavy vessels surrounding hair follicles, and hair follicles filled with yellowish keratotic plugs. In contrast, Reinehr et al. [28] recently found that erythema and white opaque scales (Fig. 4a-d) are common features of nonfacial AK, with homogenous brown pigmentation for the pigmented variant. Pigmented AKs on the face generally present the annular-granular pattern. However, Akay et al. [29] pointed out that pigmented AK lesions share several
Fig. 3 Dermoscopic features of pigmented basal cell carcinoma lesions. Dermoscopic images (original magnification $\times 20$, Fotofinder systems) showing ulceration and multiple gray dots (white arrows) (a); mapleleaf area (black arrows), spokewheel-like area, concentric structures (white arrowheads) (b, high magnification in c); ovoid nests (white arrows) (d); spoke-wheel-like area (e, high magnification in f). Photograph of a small pigmented lesion and angiomas (g) and the corresponding dermoscopic image (h) showing a maple-leaf-like area (high magnification in $\mathbf{i}$ )

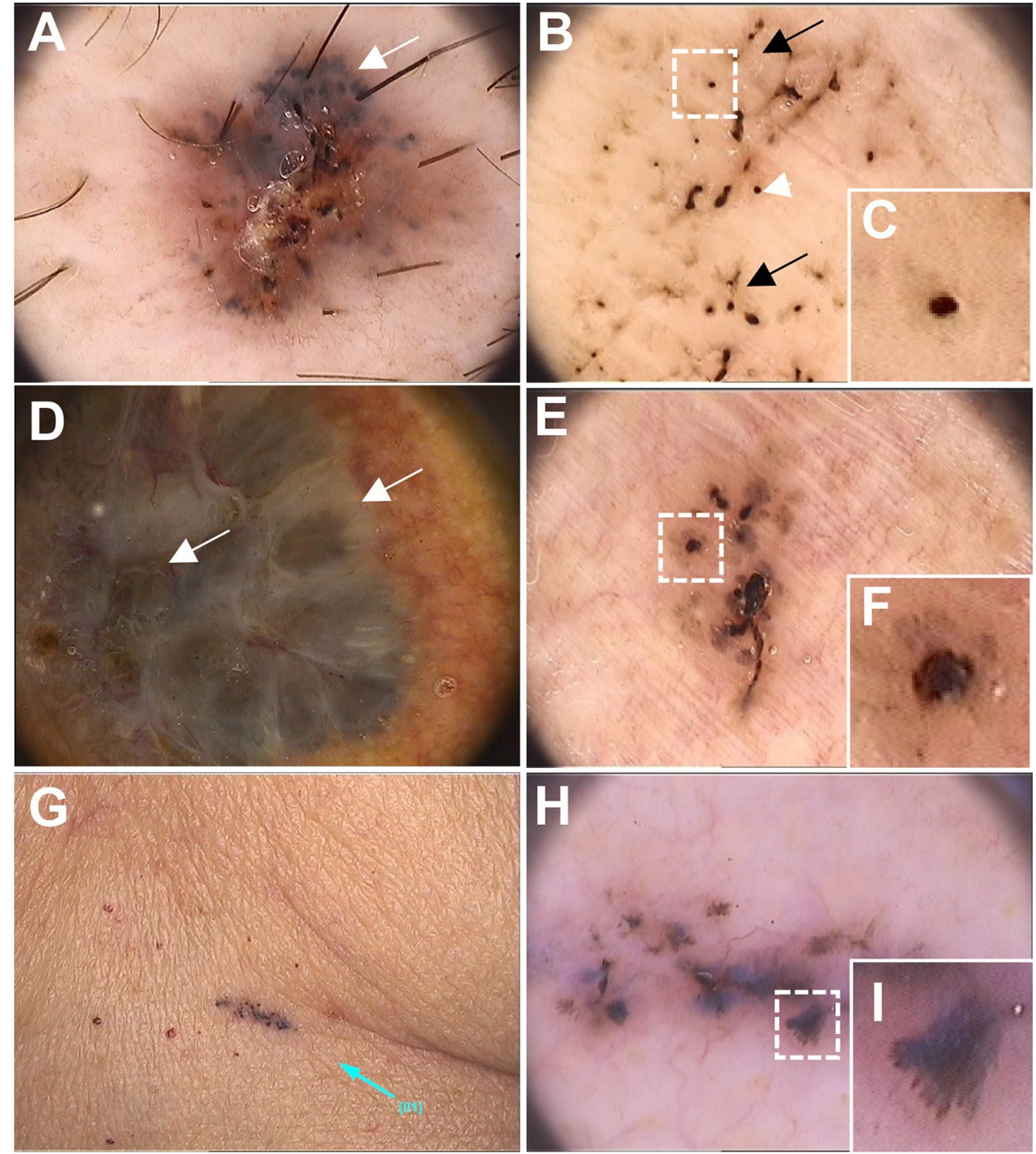


Table 2 Clinical and dermoscopic features of BCC and keratinocytic lesions and potential therapies

\begin{tabular}{|c|c|c|c|}
\hline Lesion & Clinical features & Dermoscopic features & Potential therapy \\
\hline \multicolumn{4}{|l|}{ BCC subtypes } \\
\hline Nodular & Nodular & $\begin{array}{l}\text { Arborizing telangiectasias, ulceration } \\
\text { Ovoid nests, other pigmented structures }\end{array}$ & $\begin{array}{l}\text { Nonsurgical therapy could be considered for thin } \\
\text { and small lesions, but PDT should be avoided } \\
\text { for pigmented lesions }\end{array}$ \\
\hline Superficial & Flat/scaly & $\begin{array}{l}\text { Superficial fine telangiectasias, multiple ero- } \\
\text { sions } \\
\text { Pigmented structures (but not ovoid nests) }\end{array}$ & $\begin{array}{l}\text { Nonsurgical therapy could be considered, but } \\
\text { PDT should be avoided for pigmented lesions }\end{array}$ \\
\hline Infiltrative & $\begin{array}{l}\text { Plaque (ill-defined } \\
\text { borders) }\end{array}$ & $\begin{array}{l}\text { Arborizing vessels (finer and scattered), } \\
\text { ulceration } \\
\text { Ovoid nests, blue-gray dots }\end{array}$ & Surgery \\
\hline \multicolumn{4}{|c|}{ Keratinocytic lesion subtypes } \\
\hline $\mathrm{AK}$ & $\begin{array}{l}\text { Erythematosquamous } \\
\text { plaques }\end{array}$ & $\begin{array}{l}\text { Facial AK: 'strawberry', granular pattern } \\
\text { Nonfacial AK: white scales and erythema }\end{array}$ & $\begin{array}{l}\text { Nonsurgical methods are recommended for } \\
\text { facial and nonfacial AKs and can be combined } \\
\text { with surgical ablation }{ }^{\mathrm{a}} \text { for nonfacial AKs }\end{array}$ \\
\hline $\begin{array}{l}\text { Intraepidermal car- } \\
\text { cinoma or Bowen's } \\
\text { disease }\end{array}$ & $\begin{array}{l}\text { Erythematosquamous } \\
\text { plaques }\end{array}$ & $\begin{array}{l}\text { Unpigmented variant: glomerular ves- } \\
\text { sels + yellowish scales } \\
\text { Pigmented variant (up to } 6 \% \text { of cases in the } \\
\text { study by Cameron et al. [31]): linear pig- } \\
\text { mented structures }\end{array}$ & $\begin{array}{l}\text { Nonsurgical methods could be considered, but } \\
\text { PDT should be avoided for pigmented lesions }\end{array}$ \\
\hline $\begin{array}{l}\text { Invasive SCC/keratoa- } \\
\text { canthoma }\end{array}$ & Nodular & $\begin{array}{l}\text { White circles, white color polymorphic/ } \\
\text { thrombosed vessels }\end{array}$ & Surgery \\
\hline
\end{tabular}

$A K$ actinic keratosis, $B C C$ basal cell carcinoma, $P D T$ photodynamic therapy, $S C C$ squamous cell carcinoma

${ }^{\mathrm{a}} \mathrm{Surgical}$ ablation such as curettage or cryotherapy

clinical and dermoscopic features with lentigo maligna and lentigo maligna melanoma, supporting the need for further confirmation of the AK diagnosis by histopathology or confocal microscopy if feasible (see Zalaudek et al. [30]). For IEC, the association of dotted and glomerular vessels with yellowish opaque scales is highly indicative and defines the diagnosis in $98 \%$ of cases (Fig. 4e), whereas the pigmented variant is ambiguous and frequently requires histology to exclude a diagnosis of hypomelanocytic melanoma or pigmented BCC. In the absence of melanocytic dermoscopic criteria, the presence of brown or gray dots that may be linearly distributed, or glomerular vessels and 'cotton-candy'like keratosis, may lead to suspicion of pigmented Bowen's disease [31, 32]. Finally, invasive SCCs commonly present on dermoscopy with polymorphic/thrombosed vessels at the periphery, white to yellowish circles, white structureless zones, a keratin mass, and ulceration in the center [25, 33]. Furthermore, the presence of fast-growing lesions displaying similar dermoscopic features may be indicative of a keratoacanthoma [25].

\subsection{Confocal Microscopy: Description}

Confocal microscopy or RCM is a noninvasive technique that enables real-time examination of skin tumors at cellularlevel resolution $(0.5-1 \mu \mathrm{m})$ and provides serial optical sections of the lesion from the epidermis to the papillary dermis
(200-300 $\mu \mathrm{m}$ in depth) (Table 1). This method has been proven to be excellent for the evaluation of suspicious melanocytic lesions, reducing the number needed to excise of benign tumors, and thus improving diagnostic accuracy [34-36].

\subsubsection{Diagnosis Refinement by Confocal Microscopy}

RCM is indicated for assessing tumors that require a large field of view and a shallow depth of focus. As RCM images of transversal sections correlate precisely with dermoscopic and histopathologic images, this tool refines the diagnosis of melanocytic lesions that are difficult to diagnose [37] and increases the accuracy of melanoma diagnosis in lesions lacking specific dermoscopic features (featureless melanomas) (Fig. 5), for which dermoscopy may be of limited use [38-40].

More recently, Urvanegia et al. [41] identified a correlation between the images obtained by RCM and the different BRAF profiles of melanocytic lesions, as previously suggested by Ruini et al. [42]. In this study, BRAF V600Emutated melanomas presented distinguishing clinical, dermoscopic, and RCM features. They were more likely to be isolated from patients under 50 years of age; on dermoscopy, they more frequently presented a globular pattern with irregular globules and blotches; on RCM, hyporeflective cells in the epidermis, epidermal nests, and junctional nests were seen. In contrast, BRAF wild-type melanomas were presented by older patients (aged $>50$ years) and exhibited 


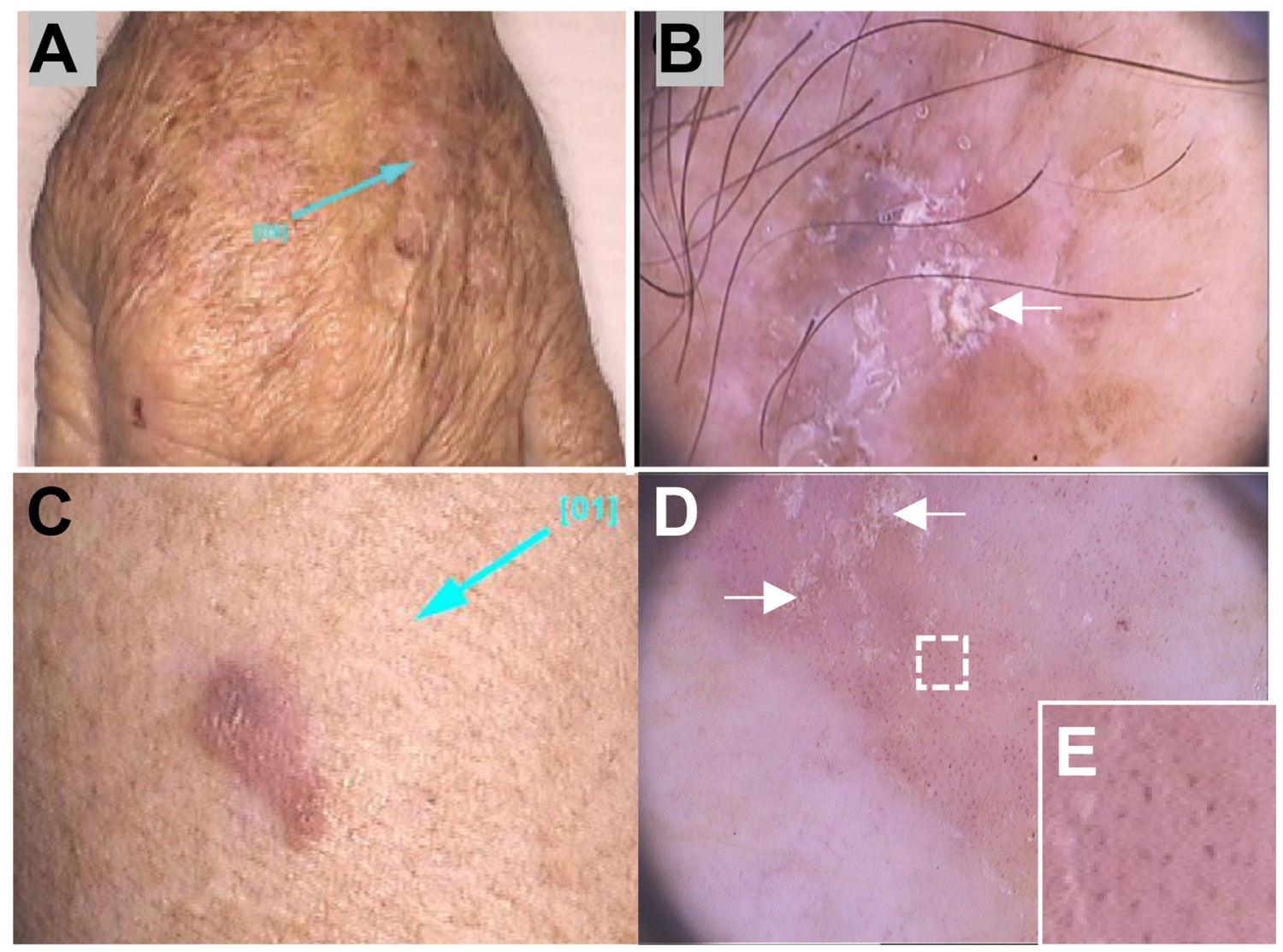

Fig. 4 Nonfacial actinic keratosis and Bowen's disease (adapted from Reinehr et al. [28]). Photographs of nonfacial pigmented actinic keratosis lesions on the dorsa of the hand (a) and the corresponding dermoscopic image (original magnification $\times 20$ ) with opaque white

an atypical network on dermoscopy with sparse irregular globules, radial projections, irregular pigmentation, a veil, and peppering. Finally, on RCM, they also revealed specific features, such as a thin network pattern, junctional thickening due to atypical isolated cells, and an atypical meshwork.

Reflectance confocal microscopy can also be used to refine the diagnosis of $\mathrm{BCC}$ and other nonmelanocytic tumors. For BCC, RCM shows an excellent correlation with histology (Fig. 6). For keratinocytic lesions, Zalaudek et al. [30] used dermoscopy and RCM to determine and correlate a morphologic graded pattern of facial AK with three stages: (1) a red pseudonetwork; (2) the strawberry-like pattern; and (3) structureless white-yellow areas. As mentioned above, the early diagnosis of these AK lesions is important because they may transform into in situ or invasive SCC. Regular monitoring is therefore advised for high-risk AK patients (Fig. 7).

As a result of its strong correlation with histology, RCM improves the accuracy of the differential diagnosis of benign versus malignant melanomas, as well as the characterization of some BCC and AK subtypes. Using this RCM technique, the dermatologist may avoid the biopsy of a benign tumor and can adapt the therapy to the severity of the lesion. scales (arrows) and homogenous brown pigmentation (b) (from Reinehr et al. [28]). Bowen's disease photograph (c) and dermoscopic image showing yellowish scales (arrows) (d) and glomerular vessels at high magnification (e) (Renato Bakos; personal images)

\subsection{Optical Coherence Tomography (OCT): Description}

OCT, based on the principle of interferometry, uses a lowcoherence source of light with a relatively long wavelength to image nontransparent tissues. In contrast with RCM, conventional OCT allows examination of skin lesions at a structural resolution (approximately $10 \mu \mathrm{m}$ ) and generates serial axial images reaching deep down to the reticular dermis (a depth of approximately $2 \mathrm{~mm}$ ) (Table 1) [43]. This more recent technique has been used to analyze nonmelanocytic tumors, with a large number of studies on BCC [44]. Speckle-variance OCT (SV-OCT) has recently been developed and has been shown to be capable of detecting microscopic vascular changes occurring in melanocytic lesions and other skin tumors [45].

\subsubsection{Diagnosis Refinement with OCT}

OCT can be particularly useful for distinguishing between superficial and infiltrative BCC lesions, as illustrated in Fig. 6. 

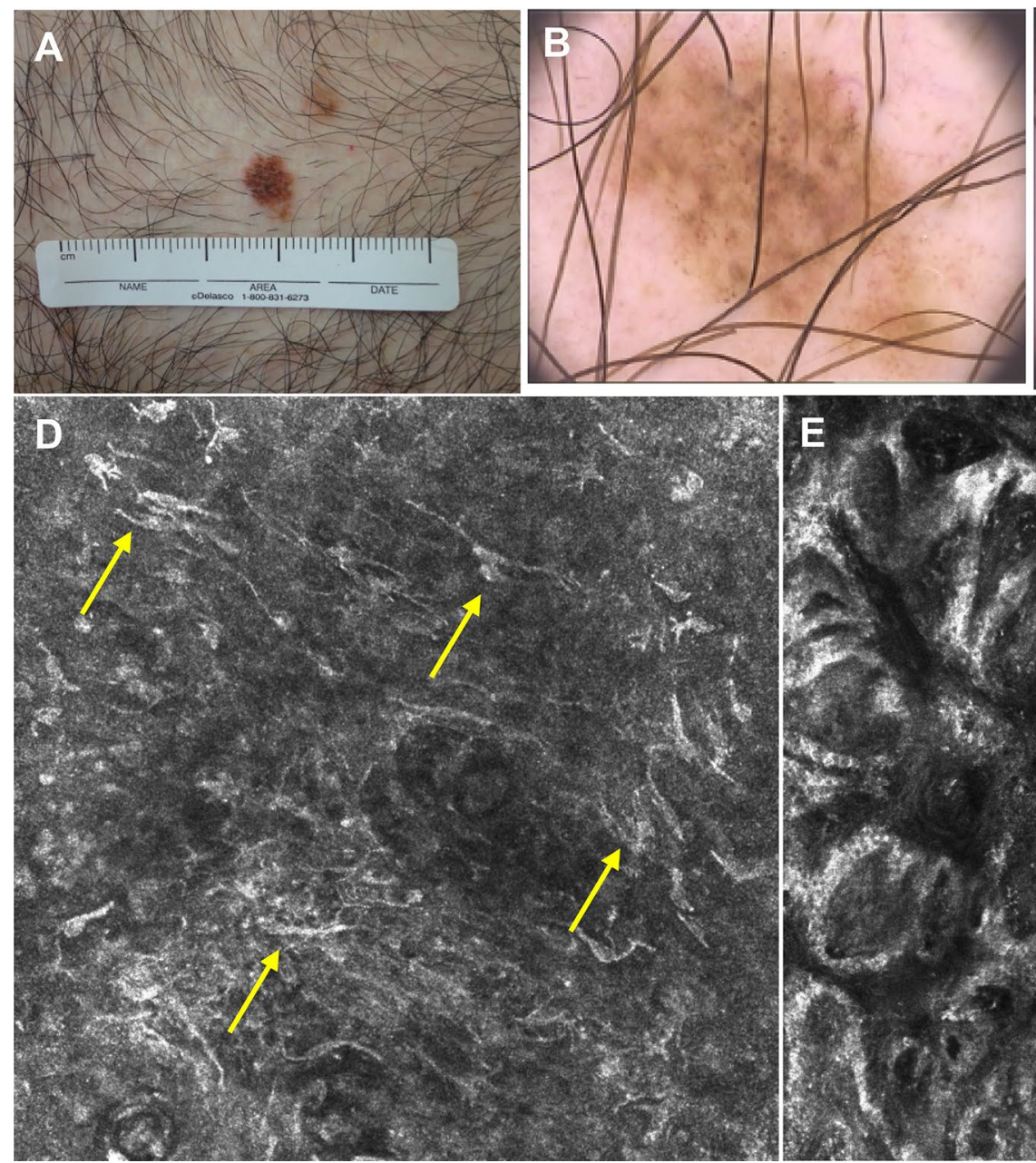

Fig. 5 Refinement of the diagnosis of 'featureless melanoma' by RCM. Clinical (a) and dermoscopic images [first examination (b) and after 6 months of follow-up (c)] of a melanocytic lesion on a patient with atypical nevi syndrome with no previous history of melanoma. The lesion presented a slight change in size and color over 6 months, but showed no specific melanoma features on dermoscopy. In the epidermis, the RCM image (d) (individual image, $0.5 \times 0.5 \mathrm{~mm}$ ) shows an atypical honeycomb pattern and widespread pagetoid infiltration

The technology is still under development for analysis of melanocytic tumors. Blumetti et al. [46] investigated whether specific OCT patterns could be associated with benign versus malignant melanocytic lesions. This study showed that compound nevi presented a hyporeflective band in the dermis and visualization of collagen was preserved, whereas in situ melanomas were characterized by epidermal shadows (eight of ten cases) (Fig. 8). The authors also found that shadows and loss of bright collagen were specific to invasive melanomas compared with compound nevi [46]. This study therefore suggests that OCT may improve the noninvasive diagnosis of melanocytic lesions (Fig. 8).

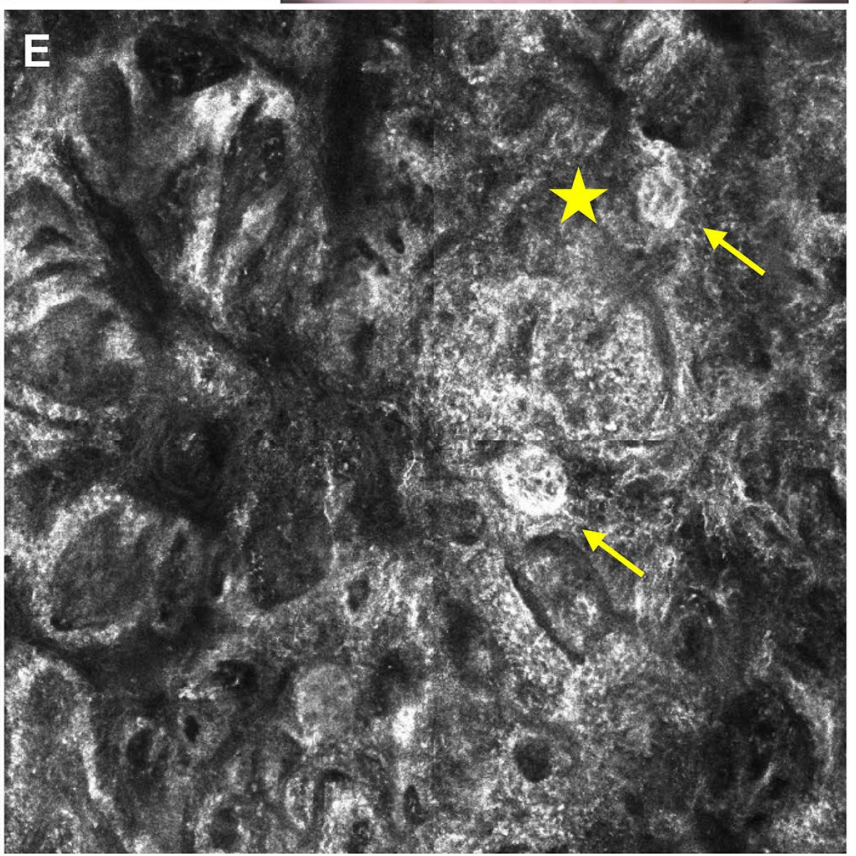

of dendritic atypical cells (arrows). At the dermal-epithelial junction, the RCM image $(\mathbf{e})(1.0 \times 1.0 \mathrm{~mm})$ shows an atypical meshwork pattern, clusters of dendritic atypical cells (star) at the papillae, and atypical junctional nests (arrows). The histopathologic analysis resulted in diagnosis of a superficial spreading melanoma (Breslow $0.25 \mathrm{~mm}$ ). Images kindly provided by Dr. Juliana Tavoloni Braga (AC Camargo Cancer Center). RCM reflectance confocal microscopy

\section{Skin Cancer Treatment and Monitoring of Response to Treatment}

\subsection{Melanoma}

Upon melanoma diagnosis, surgical resection of the lesion is mandatory. RCM may be used for presurgical mapping and postsurgical evaluation of the borders during micrographic Mohs surgery [47], thus reducing the number of procedures needed to excise the lesion and minimizing the effect of the surgery on the patient's wellbeing. Noninvasive diagnostic techniques (dermoscopy and RCM) may also be applied to monitor treatment response. 
Fig. 6 Refinement of the diagnosis of a superficial basal cell carcinoma lesion with confocal microscopy and optical coherence tomography. Clinical image of an erythematosquamous lesion on the lower eyelid (a). The dermoscopic image (b) shows erythema and scaling, and the confocal image (c) (individual image; $0.5 \times 0.5 \mathrm{~mm}$ ) reveals a 'streaming pattern' of cells (elongated keratinocytes following the same axis) in the epidermis (white arrows). The optical coherence tomography image (d) shows epidermal hyporeflective thickening with dark borders and the correspondence to histopathology (hematoxylin-eosin stain) (e) revealing basaloid nests attached to the epidermis (yellow arrows). Images kindly provided by Dr. Elimar Gomes (AC Camargo Cancer Center)
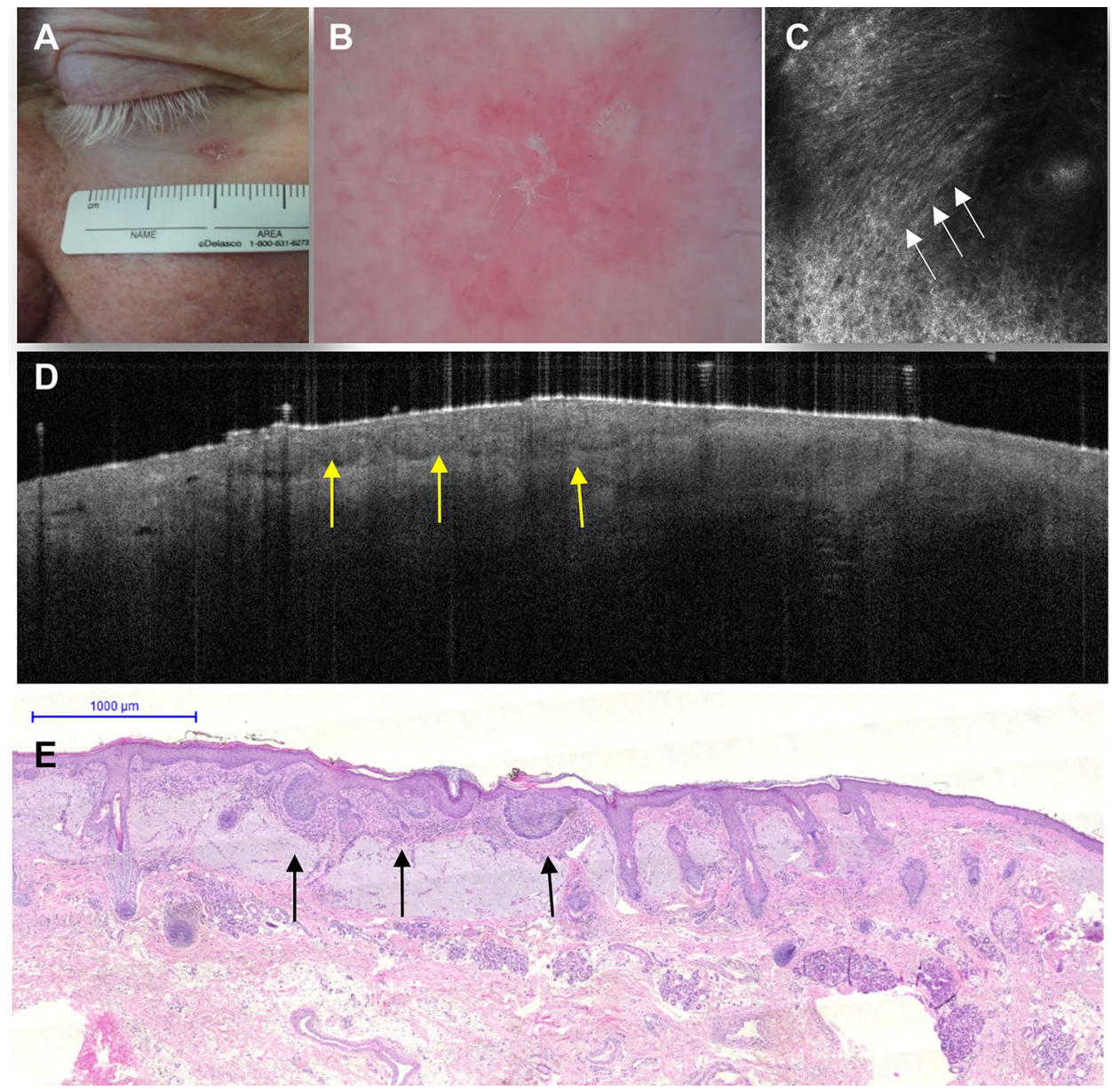

\subsection{Nonmelanoma Skin Cancers}

\subsubsection{Basal Cell Carcinoma}

Surgical methods continue to be the standard of care for the majority of the BCCs. Nevertheless, the combined clinical and dermoscopic evaluation of a lesion can frequently infer the BCC subtype, which determines further treatment choices (Table 2). Thin and small BCC lesions may respond well to nonsurgical therapies such as photodynamic therapy, whereas large and thick lesions require surgery (Table 2). Nonetheless, it should be noted that photodynamic therapy is not effective for pigmented lesions [48] due to light absorption. Besides treatment choice, dermoscopy is also helpful in monitoring the patient's response and follow-up of this kind of lesion. More recently, OCT has been used as an auxiliary tool to delineate $\mathrm{BCC}$ margins in lesions that were eligible for micrographic Mohs surgery, and has been used to delineate tumors prior to excision, hence reducing the number of steps required during surgery [45].

\subsubsection{Keratinocytic Tumors}

Bowen's disease generally has a good prognosis and may be treated with topical agents or other noninvasive techniques. In contrast, an invasive SCC should be surgically removed (Table 2).

Zalaudek et al. [30] identified graded patterns of AK using dermoscopy and RCM, and proposed associating a specific treatment to each of these AK patterns. As AK lesions may progress to in situ or invasive SCC, it is crucial to find a long-term remission therapy. AK lesions may respond well to noninvasive treatments such as photodynamic therapy, 5-fluorouracil, imiquimod, or ingenol mebutate. However, Zalaudek et al. [30] suggested that hyperkeratotic and potentially transforming AK lesions may be better treated with other methods such as cryotherapy, laser therapy, shaving biopsy, or complete excision. 

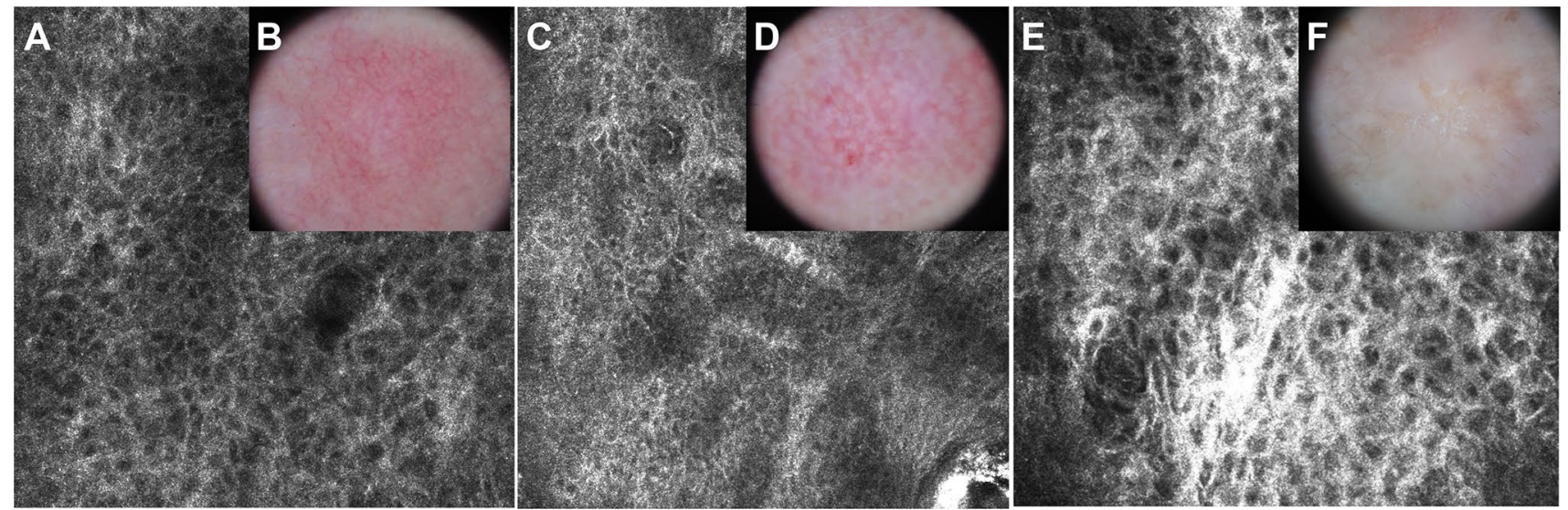

Fig. 7 Refinement of the diagnosis of keratinocytic lesions with confocal microscopy. AK on reflectance confocal microscopy (a, c, e) and dermoscopy $(\mathbf{b}, \mathbf{d}, \mathbf{f})$. Dermoscopy reveals patterns of AK of grades I (b), II (d), and III (e) showing a 'strawberry' pattern characterized by a red pseudonetwork in $\mathbf{b}$, increasing erythema and scaling in $\mathbf{d}$, and a 'starbust' pattern in $\mathbf{f}$. Confocal microscopy (epidermis,
$0.5 \times 0.5 \mathrm{~mm})$ demonstrates the progress of atypia of the honeycomb pattern, showing keratinocytes with different shapes and sizes increasing the level of atypia within the granular and spinous layer with evolution of the dermoscopy pattern of the AKs. AK actinic keratosis
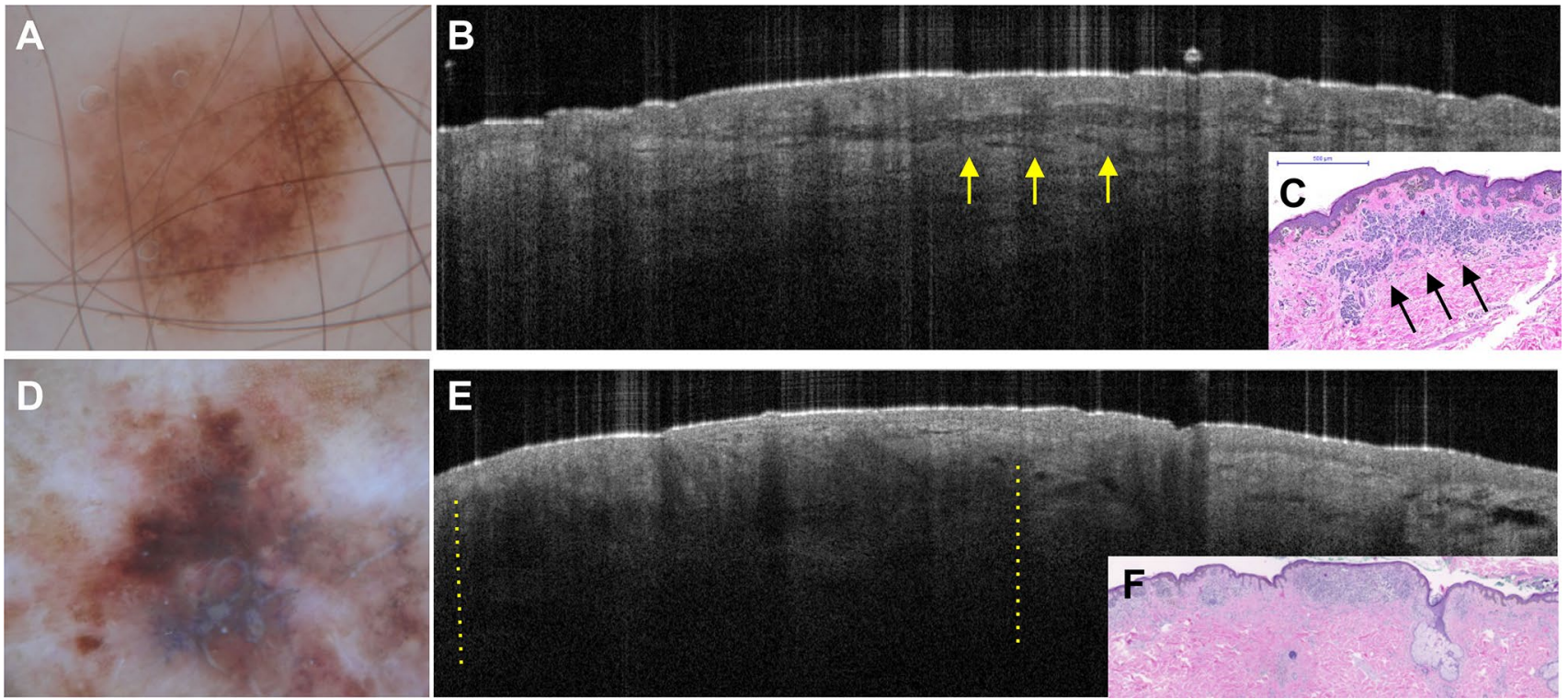

Fig. 8 Dermoscopy and optical coherence tomography images of melanocytic lesions: compound dysplastic nevus and melanoma. Dermoscopy image a of a dysplastic nevus showing a $0.5 \mathrm{~mm}$ melanocytic lesion with an atypical network pattern. On optical coherence tomography (b), a well-demarcated hyporeflective band surrounded by normal collagen can be visualized. This structure corresponds to an intradermal melanocytic nest on histopathology (c, hematoxylineosin stain). The dermoscopy image $\mathbf{d}$ of a superficial spreading melanoma (Breslow thickness $0.45 \mathrm{~mm}$ ). The optical coherence tomography image e shows a focal loss of visualization of collagen in the dermis (shadows illustrated between yellow lines) and histopathology (f, $\times 10$ magnification)

\section{Conclusions}

Noninvasive medical imaging devices have greatly improved the accuracy of skin cancer diagnosis in real-time. Although the identification of specific dermoscopic patterns requires training, algorithm-based dermoscopy is more precise than a naked-eye clinical examination to diagnose both melanocytic and NMSCs. Nonetheless, histopathologic examination is mandatory for equivocal lesions, such as pigmented AKs and pigmented Bowen's disease, because they might present dermoscopic features similar to those of malignant melanoma. In addition, high-risk patients should be on 
regular surveillance with sequential digital dermoscopy and total-body photography to allow detection of any changes in recorded lesions and implementation of follow-up for de novo lesions. The high resolution and depth capacities of RCM and OCT, respectively, enable the dermoscopic diagnosis to be refined, with the transversal sections giving similar information to histopathologic sections. The combination of both RCM and OCT in one medical device appears to be the technique of choice for diagnosing suspicious lesions in real-time. These techniques have not only led to a reduction in the rate of surgical procedures (excision, borders) but also to an increase in the use of noninvasive therapies, such as topical agents or photodynamic therapy. Furthermore, the response of the patient to the treatment can be easily monitored with the same noninvasive medical device, thereby enabling further modulation of the therapy.

Acknowledgements The authors thank Marielle Romet and Céline Zimmer (Synergy Pharm) who provided medical writing assistance funded by Laboratoires dermatologiques Avène, as well as Dr. Juliana Tavoloni Braga and Dr. Elimar Gomes of the AC Camargo Cancer Center who kindly provided the images for Figs. 5 and 6, respectively.

\section{Compliance with Ethical Standards}

Funding Medical writing assistance was funded by Laboratoires dermatologiques Avène. Marchiori Bakos, Tatiana Pinto Blumetti, Rodrigo Roldán-Marín, and Gabriel Salerni received funds from Laboratoires dermatologiques Avène for traveling to and presenting at the conference.

Conflict of interest Renato Marchiori Bakos, Tatiana Pinto Blumetti, Rodrigo Roldán-Marín, and Gabriel Salerni declare that they have no conflicts of interest that might be relevant to the content of this manuscript.

Disclosure statement This article is published as part of a journal supplement wholly funded by Laboratoires dermatologiques Avène.

Open Access This article is distributed under the terms of the Creative Commons Attribution-NonCommercial 4.0 International License (http://creativecommons.org/licenses/by-nc/4.0/), which permits any noncommercial use, distribution, and reproduction in any medium, provided you give appropriate credit to the original author(s) and the source, provide a link to the Creative Commons license, and indicate if changes were made.

\section{References}

1. Pehamberger H, Steiner A, Wolff K. In vivo epiluminescence microscopy of pigmented skin lesions. I. Pattern analysis of pigmented skin lesions. J Am Acad Dermatol. 1987;17(4):571-83.

2. Marghoob AA, Korzenko AJ, Changchien L, Scope A, Braun RP, Rabinovitz $\mathrm{H}$. The beauty and the beast sign in dermoscopy. Dermatol Surg. 2007;33(11):1388-91.

3. Kittler H, Pehamberger H, Wolff K, Binder M. Diagnostic accuracy of dermoscopy. Lancet Oncol. 2002;3(3):159-65.
4. Vestergaard ME, Macaskill P, Holt PE, Menzies SW. Dermoscopy compared with naked eye examination for the diagnosis of primary melanoma: a meta-analysis of studies performed in a clinical setting. Br J Dermatol. 2008;159(3):669-76.

5. Huerta-Brogeras M, Olmos O, Borbujo J, Hernandez-Nunez A, Castano E, Romero-Mate A, et al. Validation of dermoscopy as a real-time noninvasive diagnostic imaging technique for actinic keratosis. Arch Dermatol. 2012;148(10):1159-64.

6. Argenziano G, Cerroni L, Zalaudek I, Staibano S, HofmannWellenhof R, Arpaia N, et al. Accuracy in melanoma detection: a 10-year multicenter survey. J Am Acad Dermatol. 2012;67(1):54-9.

7. Carli P, de Giorgi V, Chiarugi A, Nardini P, Weinstock MA, Crocetti $\mathrm{E}$, et al. Addition of dermoscopy to conventional naked-eye examination in melanoma screening: a randomized study. J Am Acad Dermatol. 2004;50(5):683-9.

8. Seidenari S, Longo C, Giusti F, Pellacani G. Clinical selection of melanocytic lesions for dermoscopy decreases the identification of suspicious lesions in comparison with dermoscopy without clinical preselection. Br J Dermatol. 2006;154(5):873-9.

9. Alexandrescu DT. Melanoma costs: a dynamic model comparing estimated overall costs of various clinical stages. Dermatol Online J. 2009;15(11): 1 .

10. American Cancer Society. Survival Rates for Melanoma Skin Cancer, by Stage. 2016. https://www.cancer.org/cancer/melan oma-skin-cancer/detection-diagnosis-staging/survival-rates-formelanoma-skin-cancer-by-stage.html. Cited 1 Feb 2018.

11. Gandini S, Sera F, Cattaruzza MS, Pasquini P, Abeni D, Boyle $\mathrm{P}$, et al. Meta-analysis of risk factors for cutaneous melanoma: I. Common and atypical naevi. Eur J Cancer. 2005;41(1):28-44.

12. Ballone E, Passamonti M, Lappa G, Di Blasio G, Fazii P. Pigmentary traits, nevi and skin phototypes in a youth population of Central Italy. Eur J Epidemiol. 1999;15(2):189-95.

13. Stoltz W, Braun-Falco O, Bilek P, Landthaler M, Cognetta A. A color atlas of dermoscopy. Germany: Blackwell Science; 1994.

14. Menzies SW, Ingvar C, Crotty KA, McCarthy WH. Frequency and morphologic characteristics of invasive melanomas lacking specific surface microscopic features. Arch Dermatol. 1996;132(10):1178-82.

15. Argenziano G, Fabbrocini G, Carli P, De Giorgi V, Sammarco E, Delfino M. Epiluminescence microscopy for the diagnosis of doubtful melanocytic skin lesions. Comparison of the $\mathrm{ABCD}$ rule of dermatoscopy and a new 7-point checklist based on pattern analysis. Arch Dermatol. 1998;134(12):1563-70.

16. Argenziano G, Soyer HP, Chimenti S, Talamini R, Corona R, Sera $\mathrm{F}$, et al. Dermoscopy of pigmented skin lesions: results of a consensus meeting via the Internet. J Am Acad Dermatol. 2003;48(5):679-93

17. Salerni G, Carrera C, Lovatto L, Marti-Laborda RM, Isern G, Palou J, et al. Characterization of 1152 lesions excised over 10 years using total-body photography and digital dermatoscopy in the surveillance of patients at high risk for melanoma. J Am Acad Dermatol. 2012;67(5):836-45.

18. Salerni G, Carrera C, Lovatto L, Puig-Butille JA, Badenas C, Plana E, et al. Benefits of total body photography and digital dermatoscopy ("two-step method of digital follow-up") in the early diagnosis of melanoma in patients at high risk for melanoma. $\mathrm{J}$ Am Acad Dermatol. 2012;67(1):e17-27.

19. Salerni G, Teran T, Puig S, Malvehy J, Zalaudek I, Argenziano G, et al. Meta-analysis of digital dermoscopy follow-up of melanocytic skin lesions: a study on behalf of the International Dermoscopy Society. J Eur Acad Dermatol Venereol. 2013;27(7):805-14.

20. Watts CG, Dieng M, Morton RL, Mann GJ, Menzies SW, Cust AE. Clinical practice guidelines for identification, screening and follow-up of individuals at high risk of primary cutaneous melanoma: a systematic review. Br J Dermatol. 2015;172(1):33-47. 
21. Lucas R, McMichael T, Smith W, Armstrong B. Global burden of disease from solar ultraviolet radiation. Geneva: World Health Organization; 2006.

22. Telfer NR, Colver GB, Morton CA. Guidelines for the management of basal cell carcinoma. Br J Dermatol. 2008;159(1):35-48.

23. Lallas A, Apalla Z, Argenziano G, Longo C, Moscarella E, Specchio F, et al. The dermatoscopic universe of basal cell carcinoma. Dermatol Pract Concept. 2014;4(3):11-24.

24. Menzies SW, Westerhoff K, Rabinovitz H, Kopf AW, McCarthy WH, Katz B. Surface microscopy of pigmented basal cell carcinoma. Arch Dermatol. 2000;136(8):1012-6.

25. Zalaudek I, Giacomel J, Schmid K, Bondino S, Rosendahl C, Cavicchini S, et al. Dermatoscopy of facial actinic keratosis, intraepidermal carcinoma, and invasive squamous cell carcinoma: a progression model. J Am Acad Dermatol. 2012;66(4):589-97.

26. Pan Y, Chamberlain AJ, Bailey M, Chong AH, Haskett M, Kelly JW. Dermatoscopy aids in the diagnosis of the solitary red scaly patch or plaque-features distinguishing superficial basal cell carcinoma, intraepidermal carcinoma, and psoriasis. J Am Acad Dermatol. 2008;59(2):268-74

27. Zalaudek I, Giacomel J, Argenziano G, Hofmann-Wellenhof R, Micantonio T, Di Stefani A, et al. Dermoscopy of facial nonpigmented actinic keratosis. Br J Dermatol. 2006;155(5):951-6.

28. Reinehr CPH, Garbin GC, Bakos RM. Dermatoscopic patterns of nonfacial actinic keratosis: characterization of pigmented and nonpigmented lesions. Dermatol Surg. 2017;43(11):1385-91.

29. Akay BN, Kocyigit P, Heper AO, Erdem C. Dermatoscopy of flat pigmented facial lesions: diagnostic challenge between pigmented actinic keratosis and lentigo maligna. Br J Dermatol. 2010;163(6):1212-7.

30. Zalaudek I, Piana S, Moscarella E, Longo C, Zendri E, Castagnetti $\mathrm{F}$, et al. Morphologic grading and treatment of facial actinic keratosis. Clin Dermatol. 2014;32(1):80-7.

31. Cameron A, Rosendahl C, Tschandl P, Riedl E, Kittler H. Dermatoscopy of pigmented Bowen's disease. J Am Acad Dermatol. 2010;62(4):597-604.

32. Gutierrez-Mendoza D, Narro-Llorente R, Karam-Orantes M, Fonte-Avalos V, Martinez-Luna E, Toussaint-Caire S, et al. Dermoscopy clues in pigmented Bowen's disease. Dermatol Res Pract. 2010;2010:464821.

33. Rosendahl C, Cameron A, Argenziano G, Zalaudek I, Tschandl P, Kittler H. Dermoscopy of squamous cell carcinoma and keratoacanthoma. Arch Dermatol. 2012;148(12):1386-92.

34. Langley RG, Rajadhyaksha M, Dwyer PJ, Sober AJ, Flotte TJ, Anderson RR. Confocal scanning laser microscopy of benign and malignant melanocytic skin lesions in vivo. J Am Acad Dermatol. 2001;45(3):365-76.

35. Lovatto L, Carrera C, Salerni G, Alos L, Malvehy J, Puig S. In vivo reflectance confocal microscopy of equivocal melanocytic lesions detected by digital dermoscopy follow-up. J Eur Acad Dermatol Venereol. 2015;29(10):1918-25.

36. Stanganelli I, Longo C, Mazzoni L, Magi S, Medri M, Lanzanova $\mathrm{G}$, et al. Integration of reflectance confocal microscopy in sequential dermoscopy follow-up improves melanoma detection accuracy. Br J Dermatol. 2015;172(2):365-71.

37. Braga JC, Macedo MP, Pinto C, Duprat J, Begnami MD, Pellacani $\mathrm{G}$, et al. Learning reflectance confocal microscopy of melanocytic skin lesions through histopathologic transversal sections. PLoS One. 2013;8(12):e81205.

38. Skvara H, Teban L, Fiebiger M, Binder M, Kittler H. Limitations of dermoscopy in the recognition of melanoma. Arch Dermatol. 2005;141(2):155-60.

39. Pizzichetta MA, Stanganelli I, Bono R, Soyer HP, Magi S, Canzonieri $\mathrm{V}$, et al. Dermoscopic features of difficult melanoma. Dermatol Surg. 2007;33(1):91-9.

40. Puig S, Argenziano G, Zalaudek I, Ferrara G, Palou J, Massi $\mathrm{D}$, et al. Melanomas that failed dermoscopic detection: a combined clinicodermoscopic approach for not missing melanoma. Dermatol Surg. 2007;33(10):1262-73.

41. Urvanegia AC, Tavoloni Braga JC, Shitara D, Fregnani JH, Neves JI, Pinto CA, et al. Reflectance confocal microscopy features of BRAF V600E mutated thin melanomas detected by immunohistochemistry. PLoS One. 2017;12(6):e0179745.

42. Ruini C, Manfredini M, Pellacani G, Mandel VD, Tomasi A, Ponti G. Confocal microscopy characterization of BRAFV600E mutated melanomas. Melanoma Res. 2015;25(4):367-71.

43. Schmitz L, Reinhold U, Bierhoff E, Dirschka T. Optical coherence tomography: its role in daily dermatological practice. J Dtsch Dermatol Ges. 2013;11(6):499-507.

44. Cheng HM, Guitera P. Systematic review of optical coherence tomography usage in the diagnosis and management of basal cell carcinoma. Br J Dermatol. 2015;173(6):1371-80.

45. De Carvalho N, Ciardo S, Cesinaro AM, Jemec G, Ulrich M, Welzel J, et al. In vivo micro-angiography by means of specklevariance optical coherence tomography (SV-OCT) is able to detect microscopic vascular changes in naevus to melanoma transition. J Eur Acad Dermatol Venereol. 2016;30(10):e67-8.

46. Moraes Pinto Blumetti TC, Cohen MP, Gomes EE, Petaccia de Macedo M, de Souza Ferreira, Begnami MD, Tavares Guerreiro Fregnani JH, et al. Optical coherence tomography (OCT) features of nevi and melanomas and their association with intraepidermal or dermal involvement: a pilot study. J Am Acad Dermatol. 2015;73(2):315-7.

47. Longo C, Ragazzi M, Rajadhyaksha M, Nehal K, Bennassar A, Pellacani G, et al. In vivo and ex vivo confocal microscopy for dermatologic and Mohs surgeons. Dermatol Clin. 2016;34(4):497-504.

48. Kaviani A, Ataie-Fashtami L, Fateh M, Sheikhbahaee N, Ghodsi $\mathrm{M}$, Zand N, et al. Photodynamic therapy of head and neck basal cell carcinoma according to different clinicopathologic features. Lasers Surg Med. 2005;36(5):377-82.

49. Tkaczyk E. Innovations and developments in dermatologic noninvasive optical imaging and potential clinical applications. Acta Derm Venereol. 2017;Suppl 218:5-13. 